\title{
BUILDING DATABASEHASIL EVALUASI BELAJAR SISWA PADA SMAN 2 KOTA TANGERANG
}

\author{
Padeli $^{1}$, Mulyati $^{2}$, Alvega Awanda ${ }^{3}$ \\ AMIK Raharja Informatika, STMIK Raharja, STMIK Raharja ${ }^{1,2,3}$ \\ Jl. Jenderal Sudirman No. 40, Modernland, Tangerang ${ }^{1,2,3}$ \\ email : padeli@raharja.info ${ }^{1}$, mulyati@raharja.info ${ }^{2}$, alvega@raharja.info ${ }^{3}$
}

\begin{abstract}
Abstrak
Perancangan sistem database merupakan sebuah kebutuhan sistem yang diperlukan dalam pengelolaan nilai siswa pada SMAN 2 Kota Tangerang untuk membantu pemrosesan dan penyimpanan nilai siswa sebagai media arsip nilai di mana sistem penyimapanan nilai yang berjalan saat ini masih menggunakan Buku Induk Sekolah (BIS). Hal ini menyebabkan beberapa masalah seperti menumpuknya beban kerja pada satu pihak dan waktu operasional yang cukup lama ketika input nilai. Dalam mengatasi masalah tersebut maka dibutuuhkan sebuah sistem yang mampu menunjang proses penginputan nilai yang selama ini berfokus pada operator/admin sebagai pihak yang mengintput nilai kedalam data sekolah. Sehingga untuk menganalisis permasalahan yang terjadi maka diperlukan beberapa metode penelitian diantaranya metode pengumpulan data, observasi, dan literature review. Lalu data yang telah ada dilanjutkan dengan metode SWOT, metode ini menjelaskan tentang kekurangan dan kelebihan sistem, lalu didapatkannya solusi penyelesaiannya. Sesudah melakukan analisis, lalu dilanjutkan dengan proses perancangan sistem.
\end{abstract}

Kata kunci: sistem, database, arsip.

\begin{abstract}
Design of database system is a requirements that are needed in the management of student scores on SMAN 2 Tangerang to assist in the processing and storage of the archive as media student's score the value where the value of the storage system that runs currently still using archive book (BIS). This causes problems such as a stacking of work load on the one hand and the long operational time when input the score. In addressing the problem then it needs a system that is able to support the process of insertion of the value that has been focused on the operator/admin as the parties enter the value into the data of the school.So to analyze the poblems occurred then needed some research methods include methods of data colletion, observation, and a literature review. Then the data that there has been continued with the SWOT method, this method describes the shortcomings and advantages of the system, then he obtained a solution. After doing analysis, and continued with the process of designing the system.
\end{abstract}

Keyword: system, database, archive

\section{PENDAHULUAN}

Dalam lingkungan pendidikan, nilai menjadi salah satu hal yang tidak terpisahkan dan banyak dipakai sebagai bahan pertimbangan penerimaan siswa pada tingkat pendidikan yang lebih tinggi. Siswa dengan kuantitas dan kualitas nilai yang lebih baik akan lebih mudah dalam seleksi administratif suatu institusi, baik itu pendidikan yang lebih tinggi maupun digunakan untuk melamar pekerjaan. Nilai yang baik atau buruk tidak hanya sebatas ber-manfaat pada siswa yang bersangkutan, tetapi juga memiliki efek domino pada institusi pendidikan itu sendiri. Sebagai contohnya, institusi pendidikan SMA dengan jumlah siswa yang diterima di perguruan tinggi negeri (PTN) lebih banyak melalui jalur undangan, akan menjadi lebih populer di mata halayak umum. Jalur undangan (SBMPTN) adalah jalur penerimaan maha-siswa baru dengan menggunakan nilai raport. 
Nilai menjadi hal yang tidak terpisahkan dari sekolah itu sendiri. Banyak kegunaan dari penyimpanan dan pengolahannya. Bagi pihak ketata-usahaan nilai disimpan menjadi arsip yang bernama buku induk siswa. Bagi pihak manajemen sekolah nilai dapat digunakan sebagai bahan evaluasi prestasi guru dan siswa, pemetaan mutu sekolah, data kelulusan, dan alat untuk membantu siswa dalam memasuki PTN sesuai keinginannya.

Berdasarkan kenyataan yang telah diuraikan di atas,dibutuhkan sebuah rancangan sistem database yang bertujuan menghasilkan rancangan fisik dan rancangan data untuk sistem database untuk mengelola dan menyimpan nilai siswa.ini dibuat untuk dapat menyimpan data nilai siswa dan mengolahnya menjadi informasi yang bermanfaat untuk pihak manajemen sekolah, dan juga dapat digunakan sebagai pengolah nilai ulangan harian, nilai, dan daftar kehadiran siswa yang bersangkutan, sehingga databaseini juga dapat digunakan untuk membantu pihak sekolah dalam mengelola raport. Terlebih dengan fakta bahwa sekolah memiliki sekitar 1100 siswa dengan jumlah tenaga pengajar sekitar 60 dan terdiri atas 14 mata pelajaran dengan tidak sampai 5 orang admin saat menginput nilai.

\subsection{Permasalahan}

Mengacu pada latar belakang di atas, maka penelitian ini membutuhkan suatu pokok permasalahan agar permasalahan dapat terdefinisi secara jelas sehingga didapatkan solusi dari permasalahan yang ada, serta sebagai batasan masalah agar penelitian ini dapat terfokus. Adapun permasalahan yang diajukan dalam penelitian ini yaitu:

1. Bagaimana penyimpanan data hasil evaluasi belajar siswa pada sistem yang sedang berjalan?

2. Apakah system yang saat ini berjalan sudah optimal dalam pengaplikasiannya?

3. Bagaimana merancang sebuah sistem pengolahan dan penyimpanan hasil evaluasi belajarsiswa?

\section{LANDASAN TEORI}

\subsection{Literatur Review}

Sudah banyak sekali penelitian mengenai pembahasan tentang sistem menggunakan database pada project yang dibuat untuk pembaharuan system perlu adanya studi pustaka untuk penerapan model penelitian yang akan dilaksanakan. Hal ini untuk mengetahui apa saja system yang pernah dilakukan, supaya tidak akan terjadi perulangan system yang akan dibuat, lalu melanjutkan system yang pernah dilakukan. Dan juga peneliti dapat membuat sistem menjadi lebih baik dari yang sebelumnya. Berikut literature review yang didapatkan di antaranya :

1. Penelitian saudara Munawar dengan judul "Perancangan Data Warehouse untuk Penerimaan Mahasiswa Baru" pada tahun 2013. Penelitian ini mengusulkan perancangan data warehouse untuk penerimaan mahasiswa baru serta pembelian formulir oleh calon mahasiswa yang datanya akan digunakan untuk sistem penunjang keputusan (SPK). Dalam pembangunan SPK untuk penerimaan mahasiswa baru, penting untuk mengetahui lima kekuatan yang mempengaruhi daya tarik pasar. Kelima kekuatan itu adalah pesaing, pendatang potensial, pembeli, penjual dan barang substitusi. Fokus utama analisis pada kebutuhan dalam pembangunan DW dalam penelitian ini adalah bagaimana mengetahui kebutuhan pengguna (user), tujuan perusahaan, data yang mendukung, proses untuk menjawab tujuan perusahaan dengan menggunakan data yang ada serta dukungan data eksternal agar bisa memuaskan pengguna. Dimana Pembangunan DW tidak boleh bertentangan dengan tujuan organisasi. Oleh karena itu, penting untuk mengakomodir tujuan organisasi ke dalam DW.

2. Penelitian milik Armadyah Amborowati dengan judul "Perancangan Data Warehouse pada Perpustakaan STMIK AMIKOM Yogyakarta"pada tahun 2008. Dengan menggunakan metode fase Pengembangan data warehouse. Penelitian ini bertujuan merancang data warehouse di perpustakaan STMIK AMIKOM Yogyakarta. Hasil yang didapat adalah 
diperlukan pengkodean khusus untuk id dosen dan id mahasiswa pada database data warehouse dan Field yang diperlukan pada tabel waktu sudah disesuaikan dengan kebutuhan manajemen perpustakaan.

3. Penelitian milik Eko Prasetyo, Lukito Edi Nugroho, Marcus Nurtiantara Aji dengan judul "Perancangan Data Warehouse Sistem Informasi Eksekutif untuk Data Akademik Program Studi" pada tahun 2012. Penelitian ini mengkaji perancangan data warehouse yang merupakan hasil integrasi, transformasi dan load (ETL) data dari beragam aplikasi akademis yang mengakomodasi kebutuhan adanya data history dan pengarsipan untuk mendukung sistem informasi eksekutif dalam bidang akademik. Identifikasi kebutuhan informasi tersebut menggunakan acuan format laporan eksekutif yang berasal dari borang akreditasi program studi, kuesioner Audit Mutu Akademik Internal universitas, laporan tahunan dekan fakultas, borang evaluasi diri Program Hibah Kompetisi (PHK), fitur yang tersedia pada SIE yang sudah ada, dan fitur data eksekutif yang tersedia pada web administrasi akademik universitas.

4. Skripsi saudara Lahudin dengan judul "Design Dashoboard Manhours Productivity Using Business Intelligence(BI) Concept at Base Maintenance PT GMF AeroAsia" pada tahun 2012.menjelaskanDSS ( Decision Support System)merupakan kebutuhan yang yang penting bagi pengambil keputusan ditingkat management, baik dalam middle-level management ataupun top-level management. Penggunaan database yang baik dapat menghasilkan sistem DSS sebagai sebagai penunjang keputusan yang dapat menampilkan data-data akurat, sehingga mendapatkan keputusan yang secara tepat.

\subsection{Metode Penelitian}

Dalam mengatasi kasus yang ada, lalu mengetahui sebab dan akibat yang terjadi, peneliti melakukan tiga metode penelitian, yaitu metode pengumpulan data, metode analisis, dan metode perancangan.

\subsection{Metode Pengumpulan Data}

Metode ini melakukan dengan cara mengumpulkan data yang ada. Dengan cara ini kita dapat mendapatkan informasi yang dibutuhkan agar peneliti dapat menyimpulkan masalah yang ada. Sehingga dapat data yang diperlukan untuk penelitian ini adalah :

1. Observasi

Dengan menggunakan metode ini, akan didapatkan beberapa informasi mengenai bagaimana penyimpanan arsip yang ada saat ini serta bagaimana pemanfaatannya.

2. Interview (wawancara)

Dengan metode ini kita dapat langsung mengetahui permaslahan yang ada, karena kita mendapatkan data dari orang yang memiliki kendali atas permasalahan tersebut. Dengan data yang didaptkan maka, peneliti bisa mengetahui sistem yang ada pada saat ini lebih akurat.

3. Study pustaka

Dengan metode ini dapat mengetahui bahwa suatu masalah menjadi referensi yang sudah ada lalu dikembangkan menjadi lebih baik lagi. Unutk memperoleh refernsi tersebut maka didapatkannya dari buku-buku, karangan ilmiah, laporan penelitian, skripsi, tesis, dan sumber lain-lain.

\subsection{Metode Analisis Data}

Analisis data adalah proses langkah penting dalam mendapatkan temuan hasil dari penelitian. Karena data yang sudah kita dapatkan dapatmemnnuntun kita kepada suatu penemuan, jika kita analisi dengan tepat maka dapat memnuntu peneliti menjadi inovasi teknologi terbaru. Dalam penelitian ini mengunakan teknik analisis berupa Strengths, 
Weaknesses, Opportunities, Threats (SWOT) atau dengan teknik analisis orientasi obyek Unifed Modelling Language (UML). Proses analisis tersebuat dapat dilakukan setelah pada tahapan pengumpulan data melalui observasi, wawancara, dan studi pustaka untuk mendapatkan penjelasan kebutuhan sistem yang akan dirancang. Pada proses analisa, teknik analisis yang dilakukan antara lain:

1. Analisis pengguna

Melakukan analisis terhadap user-user yang akan mengunakan sistem yang nantinya akan diketahui fungi-fungsi yang akan didaptkan user.

2. Analisis fungsional dan non-fungsional

Dengan cara ini kita dapat mengetahui fungsi sistem yang akan digunakan dan yang akan dilakukan oleh user lalu dimodelkan dengan Use Case Diagram.

3. Analisis perilaku terhadap sistem

Pada tahap ini, peneliti melakukan analisis terhadap sistem yang dirancang lalu dimodelkan melalui activity diagram dan sequence diagram.Proses memodelkan use case diagram yang berjalan menggunakan activity diagram. Sedangkanmemodelkan pesan (message) antara object dengan kronoliginya menggunakan sequence diagram.

4. Analisis sistem yang sedang berjalan

Dalam merancang sistem yang baik, maka bagi peneliti untuk mengetahui sistem yang berjalan pada saat ini dengan mendapatkan profil dari instansi, dokumen objek penelitian yang sedang dipakai, dan proses sistem yang berjalan.

\subsection{Metode Perancangan}

Dalam penelitian ini digunakan metode pengembangan sistem dengan metode SDLC (System Development Life Cycle) waterfall yang tahapan-tahapan pengerjaannya ialah sebagai berikut:

1 Perencanaan (planning)

2 Analisis (analysis)

3 Perancangan (design)

4 Implementasi(implementation)

5 Pemeliharaan (maintenance)

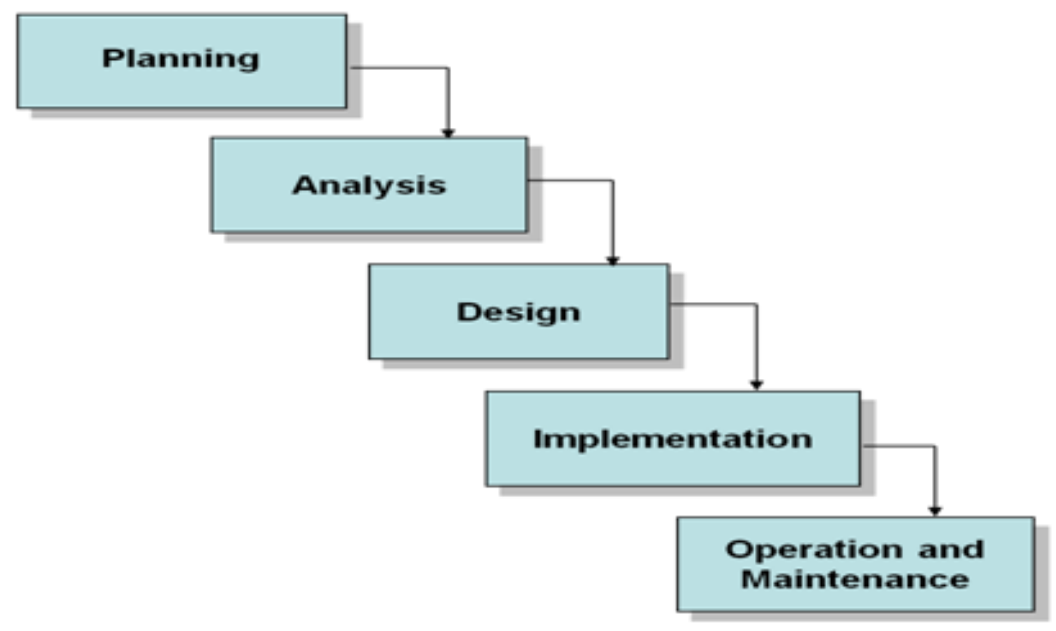

Gambar 1.SDLC waterfall 


\subsection{Metode Testing}

Setelah merancang sistem yang diusulkan maka akan dilakukan metode testing atau yang sering digunakan yaitu blackbox testing. Blackbox testing merupakan metode uji coba yang focus terhadap perangkat lunak atau software. Dengan metode ini maka dapat deiketahui kondisi mengenai sistem yang telah peneiliti buat. Metode pengujian blackbox teting untuk mengetahui kesalahan fungsi atau hilang dari sistem yang telah peneliti buat kesalahan dari interface, struktur data, maupun akses kedalam database. Dengan metode ini kita dapat terbantu dalam uji sistem.

\section{HASIL DAN PEMBAHASAN}

Berdasarkan masalah yang terjadi maka analisis pada sistem sebelumnya dijelaskan penyimpanan arsip nilai siswa belum melakukan sistem yang baik. Maka dapat terjadi masalah akibat sistem yang masih menggunakan sistem manual, Karen dalam menginput nilai kedalam buku induk sekolah masih manual dan dikerjakan oleh beberapa orang admin. Selain itu, alur pengarsipan yang panjang menyebabkan keterlambatan dalam penyelesaian pembuatan raport yang dibagikan kepada orang tua siswa maupun salinannya. Karena hal seperti itulah banyak keluhan yang terjadi oleh orang tua siswa. Maka dari itu untuk mengurangi dari keterlambatan itu peneliti mengusulkanmembangun sistem yang berguna sebagai mengatasi permasalahan yang ada. Dalam hal ini digunakan database untuk membuat dan menyimpan data. Karena dalam database penyimpanan akan sistematik dan memperoleh data lebih cepat, akurat, dan sedikit kesalahan yang ada. Dalam hal ini peneliti sudah mengusulkan sistem yang akan dibuat dan menaruhnya dalam use case diagram dan sequence diagram yang telah dibuat.

\subsection{Use Case Diagram}

Dalam peneilitian ini peneliti membuat sistem usulan usecase diagram sebagai berikut :

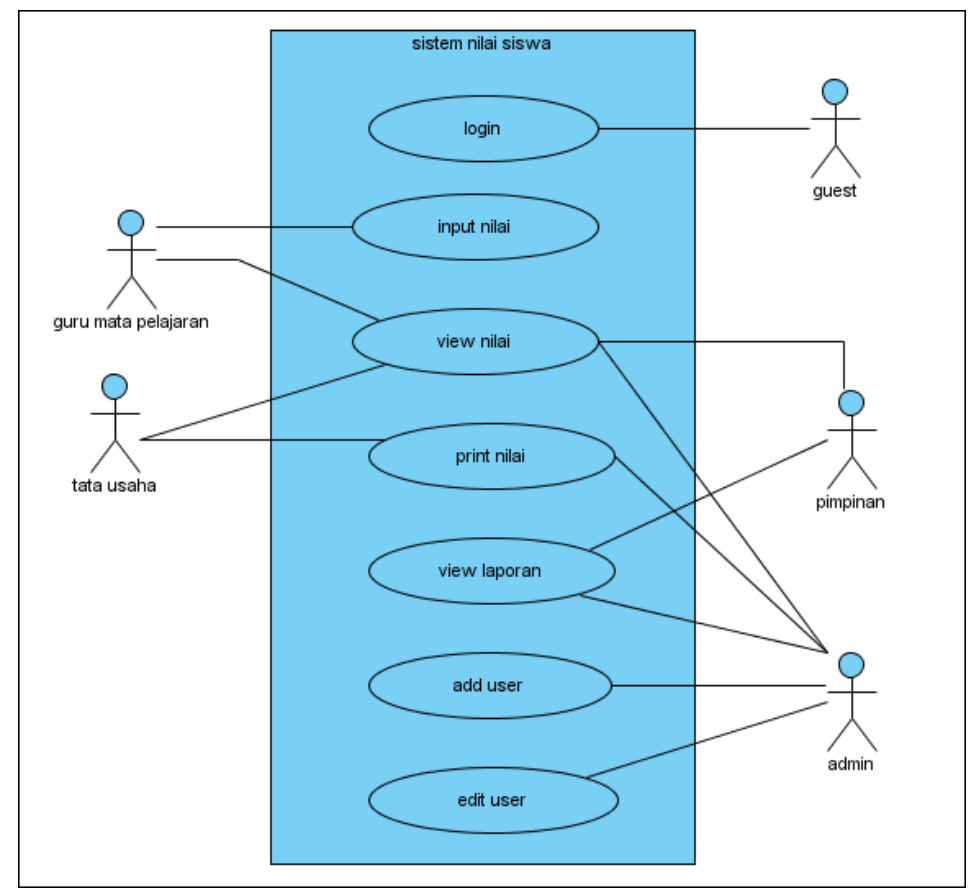

Gambar 2.use case diagram yang diusulkan 
Berdasarkan gambar diatas peneliti dapat mengusulkan sistem dalam usecase diagram dengan dijabarkan sebagai berikut:

1. Use case login

Actor: guest

Main success scenario: setelah login, guest akan memasuki homepage(halaman utama) dan terbagi menjadi empat level user, yaitu guru mata pelajaran, tata usaha (TU), pimpinan, dan admin.

2. Use case input nilai

Actor: guru mata pelajaran

Main success scenario: setiap user guru mata pelajaran dapat memasukkan nilai sesuai bidang studi yang diajarkan.

3. Use case view nilai

Actors: guru mata pelajaran, admin, tata usaha, dan pimpinan

Main success scenario: use case ini merupakan halaman utama, tiap user/actor dapat melihat nilai-nilai siswa, raport, dan lampiran raport berdasarkan kriteria tertentu. Kriteria nilai siswa ini berdasarkan mata pelajaran, kelas, semester, dan tahun. Kriteria raport berdasarkan NISN, kelas, semester, dan tahun, sedangkan lampiran raport berdasarkan NISN.

4. Use case print nilai

Actors: admin, dan tata usaha.

Main success scenario: setelah melakukan pencarian terhadap kriteria siswa, maka nilai dapat dicetak.

5. Use case view laporan nilai

Actor: pimpinan, admin

Main success scenario: pimpinan juga dapat melihat laporan tahunan dan laporan prestasi siswa.

6. Use case add user

Actor: admin

Main success scenario: admin memiliki kewenangan untuk menambah user pada tabel 'user'.

7. Use case edit user

Actor: admin

Main success scenario: admin dapat menyunting data password pada tabel 'user'. 


\subsection{Sequence Diagram}

Berdasarkan sistem yang peneliti usulkan maka dapat dibuat sequence diagram yang berbeda dari sistem sebelumnya.

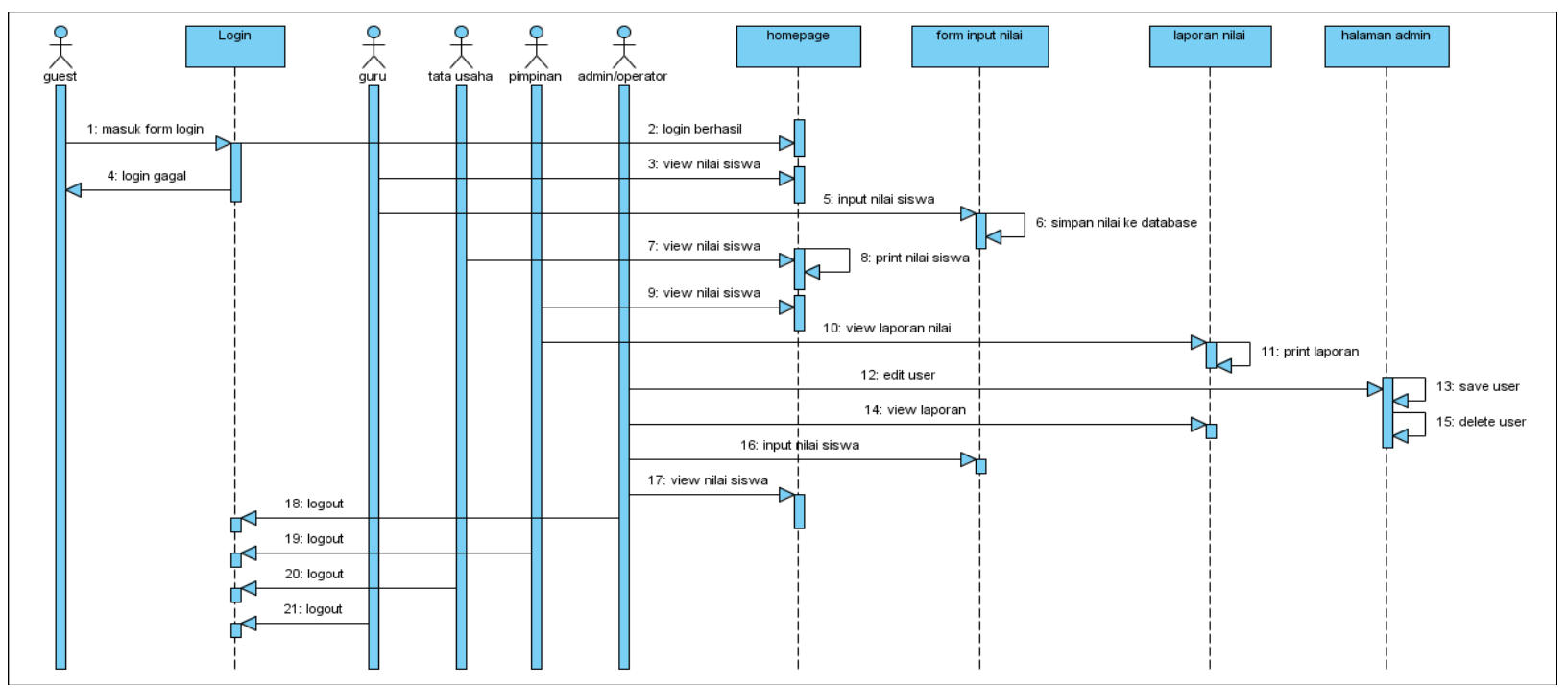

Gambar 3. sequence activity yang diusulkan berikut:

Dari gambar diatas maka dapat dijabarkan sequence diagram yang diusulkan sebagai

1. Lima actors yang melakukan kegiatan yaitu guest, guru mata pelajaran, tata usaha, pimpinan, dan admin.

2. Lima life line yang ada yaitu menu login, utama, laporan, input nilai, dan admin. Dalam menu login dapat digunakan sebagai halaman awal dengan memasukkan username dan password. Menu utama halaman setelah login berhasil masuk. Laporan untuk melihat hasil belajar dari siswa. Input nilai untuk memasukkan nilai siswa dari guru bidang studi yang terkait. Admin merupakan orang yang bertanggung jawab untuk menambah user atau menyunting password.

3. Dua puluh empat messages yang ada di dalam web tersebut, yaitu:

a. Satumessage oleh user, setelah melakukan login.

b. Dua messages oleh user login

Ketika login ada dua pemberitahuan yaitu pada saat salah memasukkan username dan password atau ketika memasukkan username dan password benar .

c. Tiga messages oleh guru bidang studi.

Guru bidang studi dapat melihat nilai, memasukkan nilai, dan logout.

d. Dua messages oleh tata usaha

Tata usaha berkewajiban untuk mencetak dokumen-dokumen yang ada dan lalu diserahkan kepada pihak lain. Contoh kasusnya ialah mencetak lampiran raport atau nilai siswa kepada wali kelas. Selain itu, tata usaha dapat melakukan proses logout.

e. Empat messages oleh pimpinan

Pimpinan atau kepala sekolah dapat melihat nilai siswa, melihat laporan nilai siswa, dan menonaktifkan program.

f. Lima messages oleh admin

Admin memiliki hak untuk menyunting data user, melihat nilai siswa, melihat laporan, menonaktifkan program (logout).

g. Satu messages oleh life line homepage

Yaitu messagesyang berupa cetak/print nilai (self-message).

h. Satu message oleh form input nilai, message ini berupa self-messages yaitu simpan nilai ke database.

i. Satumessage oleh life line laporan nilai, yaitu print laporan nilai tahunan. 
j. Dua messages oleh life line halaman admin

Admin dapat menambah user dan menyunting password user.

\subsection{Tampilan Koding}

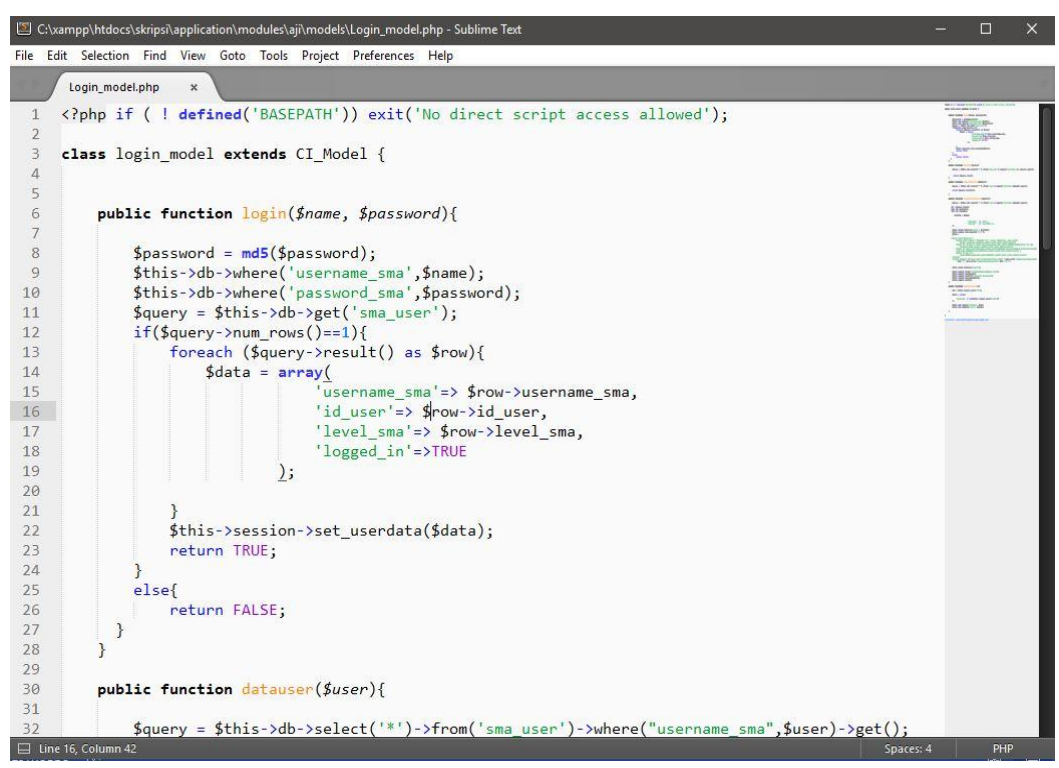

Gambar 4. Koding Model Login

Tampilan koding login untuk membangun menu login di dalam sistem yang diusulkan. Koding ini mengandung koding javascript dan php untuk membuat menu login yang baik.

\subsection{Implementasi}

Dalam sistem database ini sedang dilakukan tahap uji coba dan akan segera diimplementasikan. Sistem ini mempermudah guru unutk menginput nilai dan mendapatkan rangking terbaik dalam daftar siswa yang ada. Lalu dapat mengetahui siapa siswa yang nilainya menaik ataupun menurun. Dan ini dibuat tampilannya dibuat sederhana dan menarik supaya tidak membingungkan para guru untuk menginput nilai.

\section{Tampilan Menu Login}

Semua user yang akan melakukan input user, input nilai, ataupun melihat laporan, terlebih dahulu akan memasuki menu login. Jika ingin masuk harus sudah memiliki akun yang terdaftar pada sistem. menu tampilan login seperti dibawah ini.

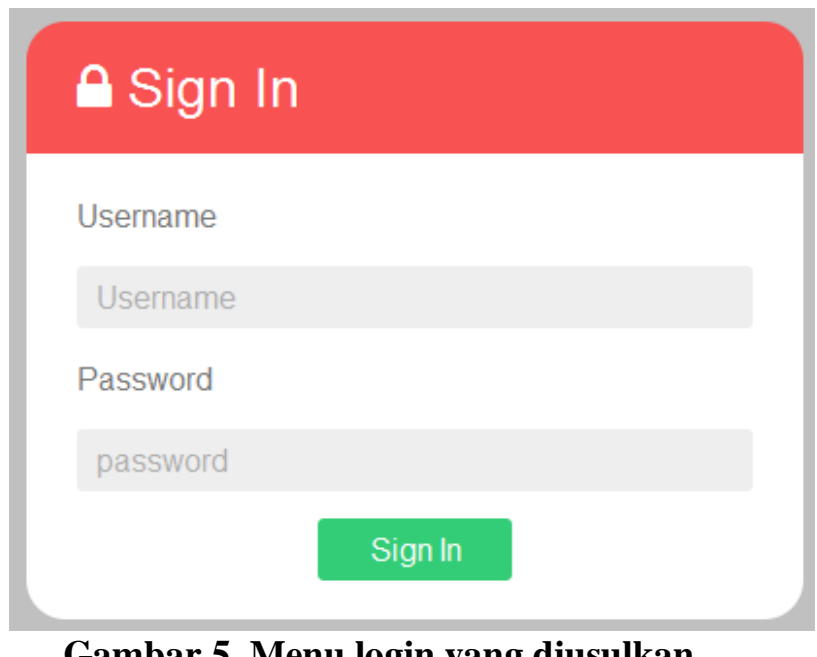

Gambar 5. Menu login yang diusulkan 


\section{Tampilan Sistem Secara umum}

Setelah berhasil masuk maka akan menampilak menu selanjutnya. Dibawah ini gambar menu sistem secara keseluruhan.

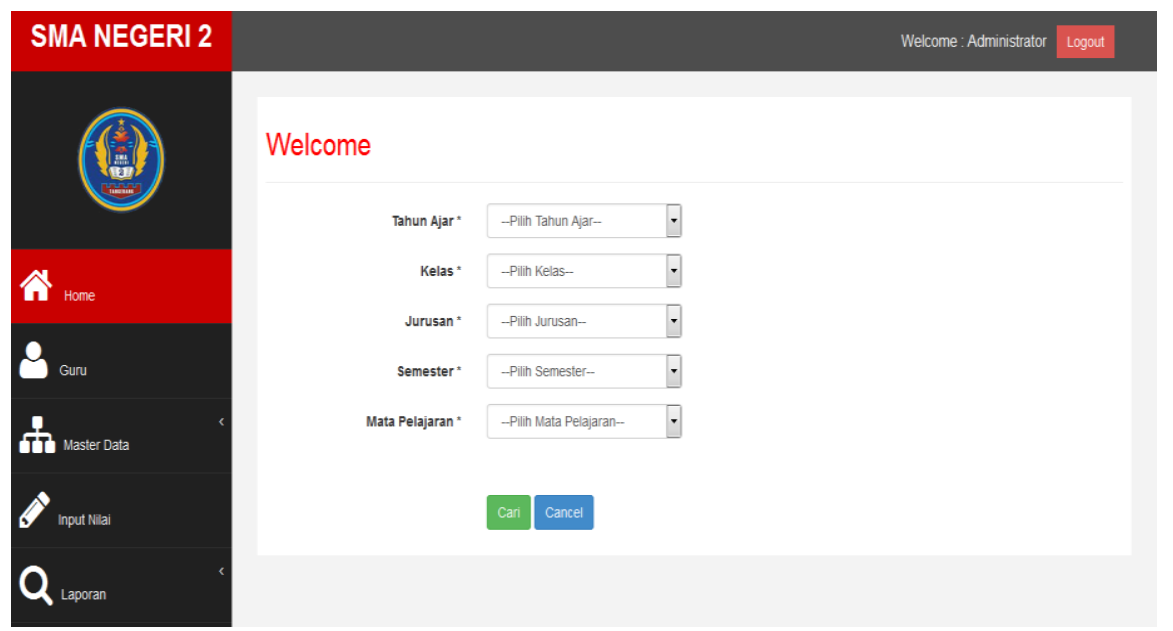

Gambar 6. tampilan website secara umum pada sistem yang diusulkan

\section{Tampilan Menu Home}

setelah login akan masuk menu home telebih dahulu. Berikut tampilan menu home.

\section{Welcome}

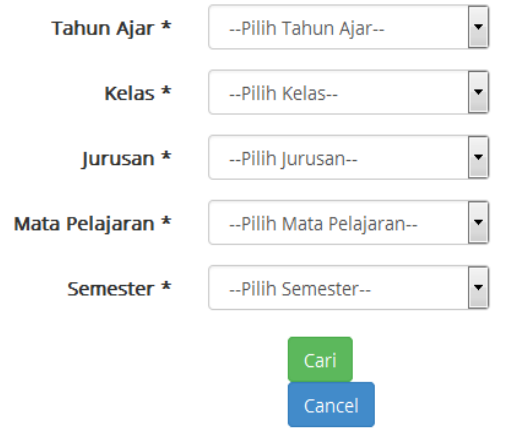

Gambar 7.Menu home yang diusulkan 


\section{Tampilan Menu Masukan Nilai}

User guru setelah login maka dapat menginput nilai. Berikut tampilan menu input nilai.

\section{Tambah Nilai Siswa}

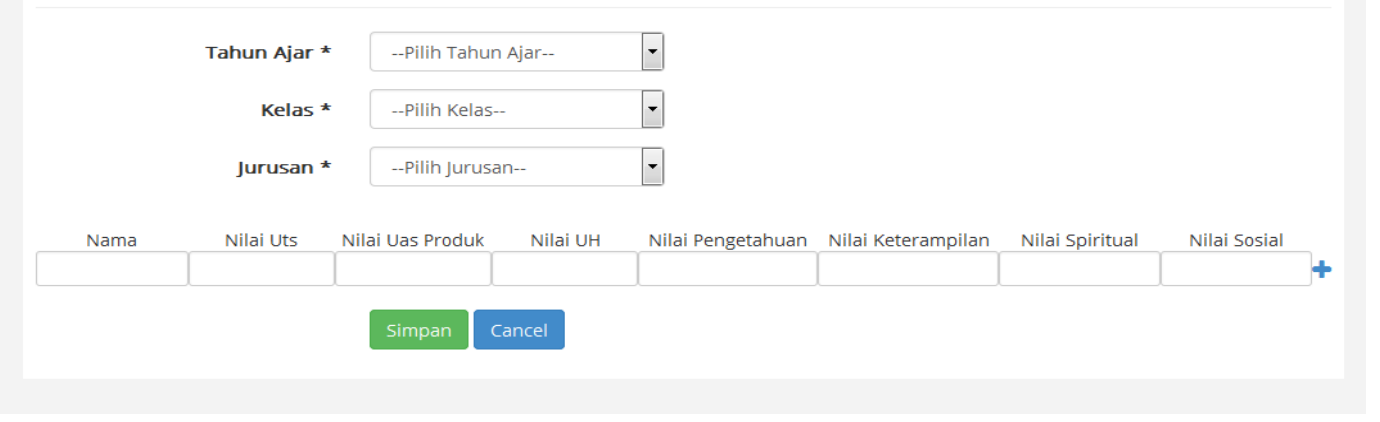

\section{Gambar 8.Menu masukan nilai yang diusulkan}

\section{Tampilan Tambah User}

Admin yang berfungsi untuk melakukan tugas maintenanceseperti melakukan perubahan data seperti menambah user. Berikut contoh tampilan dari tambah user yang disediakan pada gambar dibawah ini.

\section{Tambah User}

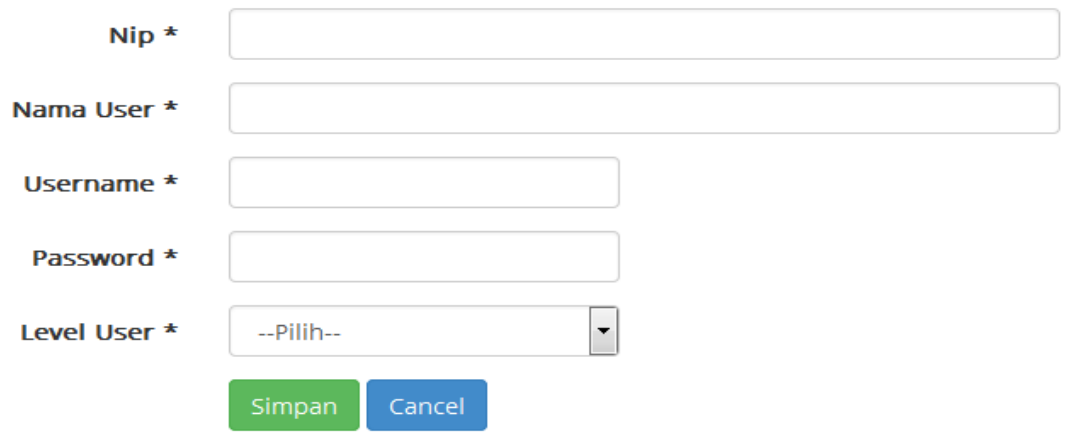

Gambar 9. tampilan tambah user pada sistem yang diusulkan 


\section{Tampilan Menu Laporan}

Dengan adanya tampilan laporan maka akan diketahui dan memudahkan pimpinan dalam melihat daftar tahunan rataan nilai siswa. Berikut tampilan menu laporan :

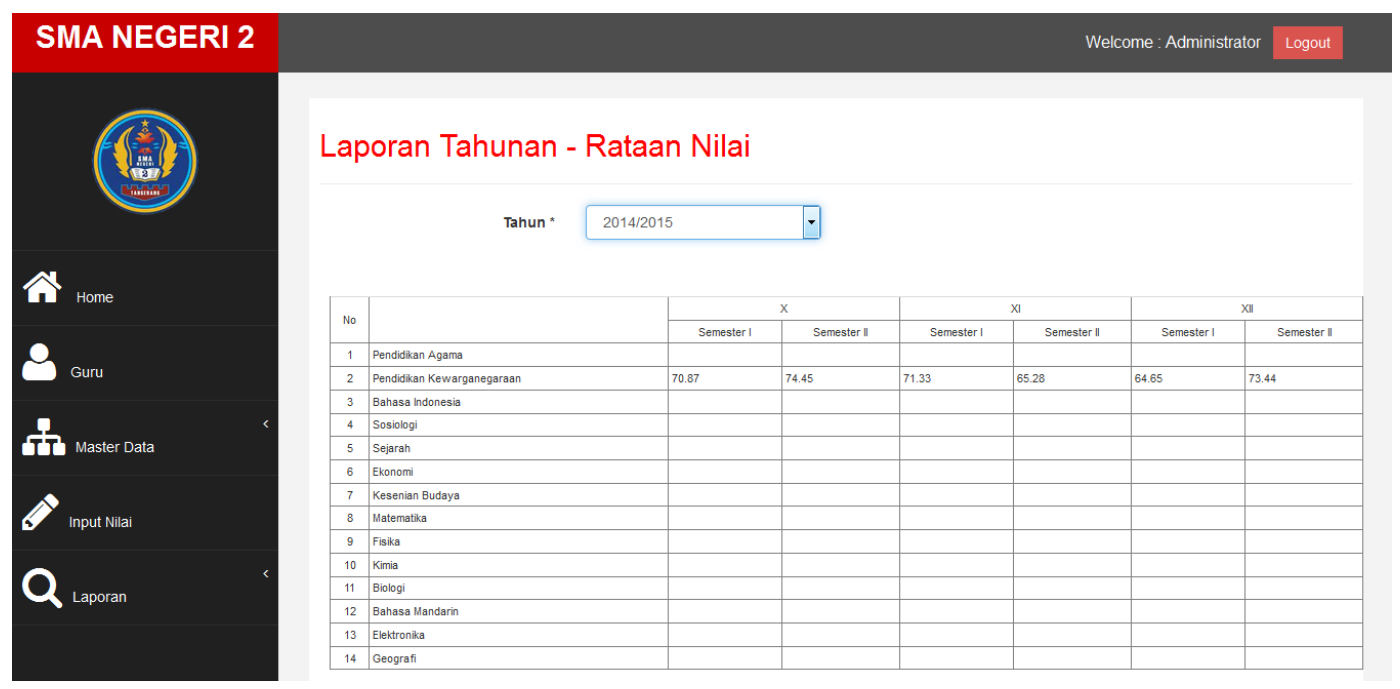

Gambar 10. Lampiran raport yang diusulkan

\section{KESIMPULAN DAN SARAN}

Mengenai masalah penyimpanan arsip prestasi atau nilai siswa, pihak sekolah belum memiliki sistem penyimpanan yang terkomputerisasi, pelaksanaan masukan, proses, atau keluarannya memang sudah menggunakan komputer, yaitu dengan menggunakan aplikasi Ms. Excel, tetapi pengolahannya masih manual dengan menggunakan rumus-rumus dan belum terotomatisasi.

Untuk proses analisis, penulis menggunakan banyak metode analisis, seperti analisis pengumpulan data menggunakan metode wawancara, observasi, dan kajian pustaka. Dengan menggunakan metode tersebut maka dapat diketahui kondisi sistem yang berjalan pada saat ini.

Setelah dapat diketahui kekurangan dan kelebihan sistem sebelumnya, maka harus membuat sistem yang baru agar dapat mengurangi kekurangan yang terjadi, tetapi tetap menggunakan sistem yang baik pada sistem sebelumnya.

Saran

Unutk mendapatkan kinerja dan data yang baik maka, diperlukannya sistem yang baru dengan sistem yang sudah terkomputerisasi. Sistem tersebut harus memanfaatkan data base sebagai penyimpanan dan web sebagai tempat penginputan.

Database dapat digunakan sebagai solusi dari masalah yang ada pada ssat ini. Dengan database maka akan mempermudah kinerja guru dalam menginput nilai dari pada menggunakan sistem manual.

Dalam sitem berbasis web maka dapat memungkinkan sistem dikembangkan kedalam data warehouse. Dengan sistem ini maka dapat membantu perbaikan dalam proses masukan ataupun keluaran sehingga tercipta sistem yang memudahkan untuk pengambilan keputusan. 


\section{DAFTAR PUSTAKA}

[1]. Amborowati, Armadyah. 2010. "Perancangan Data Warehouse pada Perpustakaan STMIK AMIKOM Yogyakarta". Yogyakarta: Jurnal DASI AMIKOM Yogyakarta. Vol 11 No 1 (2010).

[2]. Lahudin. 2012. "Design Dashoboard Manhours Productivity Using Business Intelligence(BI) Concept at Base Maintenance PT GMF AeroAsia". Laporan Skripsi Perguruan Tinggi Raharja.

[3]. Munawar. 2013. "Perancangan Data Warehouse untuk Penerimaan Mahasiswa Baru". Jakarta: Jurnal Ilmu Komputer Universitas Esa Unggul Vol 9 No 2.

[4]. Prasetyo, Eko. Nugroho, Lukito Edi Aji, Marcus N. 2011"Perancangan Data Warehouse Sistem Informasi Eksekutif untuk Data Akademik Program Studi”. Yogyakarta: Jurnal Nasional Teknik Elektro dan Teknologi Informasi. Vol 1, No 3 (2012). 